\title{
Microfoundations of dynamic capabilities for innovation: a review and research agenda
}

Lucy Fallon-Byrne* and Brian Harney

LINK Research Institute, Dublin City University, Ireland

Abstract: This paper provides a conceptual overview of the microfoundations of dynamic capabilities for innovation. A critical evaluation of dynamic capabilities theory highlights its contested nature and significant limitations in its application. Notably, there is little understanding of the mechanisms determining the origin and evolution of dynamic capabilities, while the role of employees has been neglected. In an effort to address this deficiency, the paper draws on literature from HRM and innovation management to trace the microfoundations of dynamic capabilities for innovation. This highlights the importance of incorporating the perspectives and motivation of employees as a central part of analysis and as a basis for more direct managerial interventions in building capabilities.

Keywords: creativity climate; dynamic capabilities; employees; HRM; innovation; microfoundations

(C) De Gruyter Open Sp. z 0.0.

\section{INTRODUCTION}

The issue of how to foster creativity and innovation in a systematic, dynamic and sustainable manner remains a perennial challenge for organisations (Anderson et al., 2014). Understanding of innovation has undoubtedly been advanced by dynamic capabilities theory as this has directed attention to the processes of future resourcecreation, concentrating on how to create new resources and renew existing resources in line with changes in the environment (Bowman and Ambrosini, 2003; Teece et al., 1997). Yet while the significance of dynamic capabilities is well recognised, there is less understanding of the mechanisms of how dynamic capabilities are created and operate (Barreto, 2010; Kraatz and Zajac, 2001). The dynamic capabilities framework is limited in its application because it has not yet developed sufficient understanding to link the development of capabilities with organisational strategies, which affect innovation behaviour (Ambrosini and Bowman, 2009; Cepeda and Vera, 2007; Helfat and Peteraf, 2009). Specifically, questions remain as to the nature of managerial strategies likely to encourage employee innovative behaviour of the type required to build dynamic capabilities. This becomes all the more significant in the context of a tidal pull which means employees tend to abandon creative actions in favour of habitual routines (Ford, 1996; Kiechel, 2012).

This article addresses these issues by aligning theory in the domains of dynamic capabilities and human resource management. This alignment enables more in-depth understanding of the microfoundations of dynamic capabilities for innovation (Felin and Foss, 2005, 2009; Felin et al., 2012). The original definition of dynamic capability offered by Teece and his colleagues affords some important insights in this task. They defined dynamic capability as 'the firm's ability to integrate, build and reconfigure internal and external competences to address rapidly changing environments' (Teece et al., 1997: 516). This definition is built around a number of key elements. First, this approach emphasises the central importance of strategic management illuminating that the dynamic capabilities perspective is intertwined with strategic managerial capabilities (Thompson, 2007). Second, it states that the desired outcome is to build and reconfigure internal and external competences. In this, the authors assume an evolutionary economic perspective highlighting the roles of routines, path dependencies and organisational learning (Barreto, 2010). Third, the perspective focuses on particular external environments, that is, rapidly changing environments. Fourth, the 
definition assumes that these capabilities are 'home grown' (Helfat and Winter, 2011: 1244), that is, they are built and developed rather than bought and applied. Similar to the resource-based view, these capabilities are heterogeneous because they are embedded in the firm and are unique and path dependent. Finally, the authors specify that the possession of such capabilities will lead to sustained competitive advantage. This original definition therefore aligns with many of the underpinning strategic conditions, which form the basis of organisational innovation. Aspects of the definition of dynamic capabilities have also been extended and broadened over time. Of particular relevance is the argument that dynamic capabilities are not limited to specific environmental conditions, but rather denote a firm's ability to change irrespective of context (Helfat and Winter, 2011; Lee and Kelley, 2008). Definitions have also moved to highlight a firm's 'behavioural orientation' as a basis to 'continuously integrate, reconfigure, renew and recreate its resources and capabilities' (Wang and Ahmed, 2007: 35).

This paper proceeds by highlighting the significance of dynamic capabilities for innovation before critically evaluating the extent to which the theory has fulfilled its original promise of illuminating the internal organisational systems and processes which enable firms to innovate. In this regard, it examines the contested nature of the theory itself and highlights significant limitations in its application (Barreto, 2010; Helfat and Peteraf, 2009). Key criticisms centre around the lack of explication of microfoundations and the neglect of employees (Abell et al., 2008; Eisenhardt et al., 2010; Felin and Foss, 2005, 2009; Felin et al., 2012). This raises the question as to whether the dynamic capabilities framework can address the issue of mutuality of organisational and individual needs in building innovation capability (Boxall, 2013). Following this critical review, the second half of the paper draws upon the logic of microfoundations to trace the underlying processes and practices that may provide potential foundations for developing dynamic capability. Specifically, it explores how HRM strategies and organisational climate can provide insights into how dynamic capability for innovation can be built. This approach finds support in the recent recognition that 'the dynamic capabilities framework is to some extent an approach for having the entire organisation operate in an entrepreneurial fashion' (Al-Aali and Teece, 2014: 108).

\section{THE SIGNIFICANCE OF DYNAMIC CAPABILITIES FOR INNOVATION}

Innovative organisations are faced with the continuous challenge of disturbing familiar and repetitive routines and behaviours and replacing them with more risky and uncertain actions which lead to innovation. These creative behaviours are very difficult to manage and sustain in organisations (Ekvall, 1997). Reconfiguring resources and changing routines towards innovation is not an easy task in part because people tend to abandon creative actions in favour of habitual routines (Cavagnou, 2011; Ford, 1996). The emergence of the theory of dynamic capabilities can be viewed as a considerable breakthrough in framing and conceptualising these internal change processes as it draws upon concepts such as innovation, organisational learning and knowledge management as key mechanisms for organisational change (Easterby-Smith et al., 2009; Kogut and Zander, 1992). The core underlying premise of dynamic capabilities is the capability to interact with the resource base to 'reconfigure' and 'refresh' existing resources and 'create' new ones (Ambrosini and Bowman, 2009: 29). These capabilities therefore enable the organisation to 'reflexively revisit' what it does in changing environments (Felin and Foss, 2009: 161).

While no doubt significant, the precise relationship between innovation and dynamic capabilities remains somewhat contested (Breznik and Hisrich, 2014). Wang and Ahmed (2007) conceptualise innovation capability as a 'critical component' of dynamic capability. Early work by Lawson and Samson (2001) proposed innovation capability as a higher-order integration capability, that is, the ability to mould and manage multiple capabilities. Dixon et al.'s (2014) qualitative study explores the development of dynamic capability for innovation in a Russian oil refinery. According to these authors, innovation capability can be conceptualised as 'a form of dynamic capability' (p. 187). Wang et al. (2015) focused on the behavioural inputs of organisational innovation as a means to explore innovation capability across 112 high-tech small- and medium-sized enterprises in the UK. These recent empirical studies have advanced understanding of the mechanisms through which capabilities for innovation are built (Katkalo et al., 2010) or brought to life (Zheng, 2010). This matches a focus on dynamic capability building as fostering creative performance behaviours directed towards achieving organisational goals (Montag et al., 2012). The linkage between innovation and dynamic capability is therefore important, although further understanding and application have been prevented by the abstract, intractable and complex notion of the dynamic capability concept (Dixon et al., 2014; Wang et al., 2015). 


\section{DEFICIENCIES IN THE DYNAMIC CAPABILITY FRAMEWORK}

While dynamic capabilities theory has the potential to unlock our understanding of the innovation in organisations, a fundamental outstanding question concerns precisely 'how the enterprise can keep renewing its resource base and create new capabilities' (Al-Aali and Teece, 2014: 103). Key conceptual criticisms of the dynamic capabilities framework relate to the definition of the term and its key unit of analysis. With respect to definition, there is considerable confusion surrounding the nature and essence of dynamic capabilities (Ambrosini and Bowman, 2009; Barreto, 2010). This difficulty is captured by Kraatz and Zajac who claim, that 'while the concept of dynamic capabilities is appealing, it is rather a vague and elusive one which has thus far proven largely resistant to observation and measurement' (2001: 653). The original definition suggested by Teece et al. (1997) is so broad and all encompassing so that it has been open to multiple and sometimes contradictory interpretation (Eisenhardt and Martin, 2000; Zollo and Winter, 2002). The contradiction inherent in many definitions is that for some dynamic capabilities are routines and patterns that are repeatable, reflecting regular and predictable behavioural patterns (Zollo and Winter, 2002), while for others they are strategic higher-order change capabilities which reside in the potential to change routines and patterns (Eisenhardt and Martin, 2000). Katkalo et al. (2010) argues that there is a qualitative difference between routines and dynamic capabilities in that the former seeks to minimize agency requirements, whereas the latter is founded upon the very concept of human agency as means of transforming existing routines, and even disrupting order and stability.

A second criticism of the dynamic capabilities framework concerns its primary unit of analysis. For the most part studies have sought to investigate the impact of dynamic capabilities by taking a macro, organisational level focus (Abell et al., 2008; Felin and Foss, 2005). Frequently lacking is an appreciation of the microfoundations, which provide an explanation for the origins and development of dynamic capabilities. Eisenhardt et al. define such microfoundations as: 'the underlying individual-level and group actions that shape strategy, organisation, and, more broadly, dynamic capabilities' (2010: 1263). Hitherto work on dynamic capabilities for innovation has been dominated by approaches which address supraindividual antecedents when seeking to account for firm-level outcomes. Ultimately, explication of dynamic capabilities requires analysis which looks both 'inward and downward' (Ployhart and Hale, 2014: 152). The logic of microfoundations exposes the limitations of an exclusive, macro higherorder focus and instead invokes that 'individuals and their interactions are central for understanding organisations and social systems' (Barney and Felin, 2013: 145). Through explicating the microfoundations of dynamic capabilities, it may be possible to more clearly identify the underlying organisational 'processes and competencies' (Eisenhardt and Martin, 2000: 1107) which underpin the evolution and development of dynamic capabilities (Dosi, 1988). To date debate has been somewhat consumed with identifying and defining dynamic capabilities to the neglect of such formative considerations (Easterby-Smith et al., 2009; Kraatz and Zajac, 2001). Overall, dynamic capabilities have largely been understood in an abstract manner which affords little sense of the role of human agency. As a consequence, the practical implications of the dynamic capability logic remain significantly underspecified.

\section{MICROFOUNDATIONS OF DYNAMIC CAPABILITIES FOR INNOVATION}

There is a growing recognition that further advancement in explicating dynamic capabilities will come from more microunderstanding of the formation and transformation of capabilities (e.g. Wei and Lau, 2010). Barney and Felin (2013: 149) recently concluded that 'further understanding of organisational capability and heterogeneity ought to rest on questions of microfoundations: how capabilities are built'. Some have attempted to address the issue of microfoundations, albeit with limiting degrees of success. Most notably, Teece (2007) proposed to examine the microfoundations of dynamic capabilities and identified these as sensing and shaping capabilities, seizing capabilities and managing threats and reconfigurations. However, arguably these are in themselves higher-order capabilities so that Teece merely provides a more detailed description of the dynamic capabilities themselves rather than the processes which underpin them. In this, Teece has done what many others have done in attempting to proffer explanations at the same level as higher-order capabilities (Felin and Foss, 2005). Laamanen and Wallin (2009) note that strategic attention and decision making affect the development of capabilities at different levels but they do not offer explanations on the origins or microfoundations of these capabilities. Eisenhardt et al. (2010) explore the microfoundations of performance in dynamic environments and 
highlight the role of leadership emphasising higher order thinking and expertise, abstraction, cognitive variety and interruptions in favouring flexibility over efficiency.

In the main insights related to microfoundations of dynamic capabilities have focused at the managerial level, encompassing entrepreneurial managers (Teece, 2012) or distinct groups such as innovation project managers (Lee and Kelley, 2008). This narrow focus is limiting as dynamic capability theory is inherently concerned with human behaviour and motivation, for example, routines, path dependencies and organisational learning (Barney and Felin, 2013; Barreto, 2010). A fundamental challenge in building dynamic change capability relates to changing the collective behaviour of employees together with their associated routines, work patterns and daily activities (Eisenhardt and Martin, 2000; Zollo and Winter, 2002). Changing behaviour on this scale and changing collective behaviour require resolute human action and endeavour on the part of management and employees. Moreover, it requires an understanding of the 'human resources' of the firm as not only including the knowledge skills and energies of their employees but also their human dispositions, personalities and emotional motivations (Boxall, 2013). Where reference is made to employees within a dynamic capabilities argument, it is from a very narrow, ideological standpoint. For example, Teece (2007: 1340) suggest that curtailing the influence of collective bargaining on wages could be seen as an element of dynamic capability in itself. Yet if knowledge is understood to be socially constructed and distributed it is important to understand how organisations can tap into the tacit energy that resides in employees throughout the organisation (McAdam and McCreedy, 2000; Wang and Ahmed, 2007). Indeed elsewhere Teece (2012) acknowledges that capabilities are built not just on individual skills but also on the collective learning derived from how employees have worked together. Notwithstanding more recent attention to the microfoundations of dynamic capability, there remains a considerable gap in understanding the links and interactions between macro and micro levels, including an under appreciation of the significance of employee innovative behaviours (Montag et al., 2012).

\section{EXPLICATING MICROFOUNDATIONS: EMPLOYER STRATEGIES AND THE ROLE OF EMPLOYEES}

Advancing greater understanding of the microfoundations of dynamic capabilities for innovation requires crossfertilisation with domains which have valuable insights in this area; this includes human resource management and the organisational innovation literatures. The need for such complementarity was acknowledged by Teece: 'many of the issues discussed here have, in the past, fallen under the rubric of human resource management; a closer connection of these issues to strategic management would appear to be warranted' (2007: 1340). In an effort to better appreciate the internal dynamics of innovation, research from these related literatures emphasises the role of both managerial strategies and employee behaviour in fostering innovation (Wendelken et al., 2014). The architecture of HRM (Becker and Gerhart, 1996) may serve as a central means of capturing the managerial intent informing how dynamic capabilities can be built and innovation outcomes realised (Barney and Felin, 2013; Ployhart and Hale, 2014).

\section{Employer strategies for innovation}

An indicative review of the literature identifies that organisational interventions in the form of communication and consultation, positive social interaction and learning strategies are particularly significant determinants of innovation. Enabling and encouraging employee communication and consultation is an important empowerment-enhancing strategy for innovation (Lynch, 2007; Subramony, 2009). Read (2000) emphasizes how flexible structures and empowered employees are supportive of innovation, while Ramstad (2009) notes that employee involvement and participation are organisational planning and implementation is related to improved organisational outcomes. Employee involvement is also an important innovation strategy in a number of studies undertaken by Black et al. which examined the workplace practices related to organisational performance outcomes (Black et al., 2004; Lynch, 2007). Communication frequency has also been identified in the literature as an important organisational innovation strategy (García-Morales et al., 2011; Shipton et al., 2006). It therefore seems that there is an important link between the levels of communication and consultation and innovation outcomes.

A second key strategy concerns relational capital and positive social interaction (Harney and Jordan, 2008; Lee and Kelley, 2008). Building relational capital and fostering positive relationships both with customers and internally with staff and managers are notable strategies linked to innovation in the literature on organisational innovation 
(Read, 2000; Slappendel, 1996). Related to the development of good relationships are reward and appraisal systems which are seen to be beneficial and supportive of innovation efforts (Shipton et al., 2006). Relational capital has been identified as one of the important underlying processes in dynamic capability for innovation and one that aligns closely with requirements for knowledge creation and exchange (Bowman and Ambrosini, 2003; Mossholder et al., 2011; Teece, 2007). These studies would therefore suggest that there is a strong link between relational capital and innovation outcomes.

Third, purposeful learning opportunities are seen as important underlying processes in developing dynamic capability for innovation (Eisenhardt and Martin, 2000; Teece, 2007). Human capital development through workforce training and employer-guided training is also an important organisational innovation strategy (Appelbaum et al., 2000; Lam, 2005; Lynch, 2007). Snell and Morris (2014) argue that dynamic capabilities by definition are underpinned by various modes of organisational learning. Learning is a central theme in the literature on organisational innovation where innovative organisations are viewed as dynamic living learning organisations. As Cavagnou (2011) notes 'innovation reflects a process of learning' (p. 122). In determining the key capabilities required for innovation, Hage (1999) highlights learning or absorptive capacity and contends that, in essence, the learning organisation is the innovative organisation and both internal and external networks are critical in sustaining this learning capacity.

While far from exhaustive, it is clear from this indicative review that various organisational strategies may foster innovative behaviour amongst employees and have a significant impact in yielding innovation outcomes. Notably, while there is a strong emphasis on empowerment in the organisational innovation literature through employee involvement and flexible structures (Appelbaum et al., 2000; Black and Lynch, 2004; Read, 2000; Shipton et al., 2006) and this is mirrored in the innovation climate literature as evidenced by freedom, flexibility and autonomy (Amabile, 1993; Patterson et al., 2005), empowerment does not feature in the dynamic capabilities literature. A focus on these managerial interventions also finds support from the national survey of employers in Ireland (Watson et al., 2010). This highlighted that organisational interventions in the form of empowerment, relational capital and learning had a significant positive effect on innovation outcomes. Yet while these strategies reflect the intention of management, equally important is the impact of such practices in terms of how they are perceived and experienced by employees (Liao et al., 2009). Here, organisational climate can be viewed as critical mediating influence between organisational practices as intended by management and subsequent employee behaviours. This logic helps in further tracing the productivity pathway underpinning dynamic capabilities for innovation.

\section{Employee perceptions: the role of innovation climate}

An appreciation of innovation efforts at an employee level has been notably absent from research on dynamic capabilities (Allen et al., 2015). In order to assess alignment of the needs of the organisation with that of the employee and ensure 'mutuality' (Boxall, 2013), there is a need to go beyond the identification of strategies for innovation to address the meaning and significance employees attribute to such practices. While organisational innovation strategies represent the broad HR 'architecture' (Becker and Gerhart, 1996: 786) designed by management to influence employee innovation behaviour, it is the intermediate sociocognitive environment resulting from these strategies which provide evidence that they are effective (Mossholder et al., 2011; Takeuchi et al., 2007). Human resource strategies influence employee climate perceptions by symbolically framing and communicating key organisational values and behaviours (Rousseau, 1995). Climate is therefore a powerful social mechanism through which HR systems influence employee perceptions, behaviours and values, and it is an important element in understanding the impact of organisational innovation strategies on employees (Mossholder et al., 2011). As innovation climate reflects the views and perceptions of employees (e.g. Asmawi and Mohan, 2011; Sundgren et al., 2005), the strength of innovation climate is a good measure of what employees receive and experience in terms of organisational innovation inputs from the employer. In other words, a strong innovation climate demonstrates that the strategies articulated and designed by managers are actually being enacted (Anderson and West, 1998). It would be expected that innovation climate would be strongly linked with other organisational innovation strategies reflecting the presence of an innovation dynamic where there is a synergy between different policies and inputs from managers and employee perceptions and awareness of these inputs (cf Boxall, 2013).

Innovation climate is an important element in the complex interaction between the individual's dispositions towards, and motivation for creativity and the design of the organisational contextual factors which support creativity and innovation (Amabile, 1993; Ford, 1996; Takeuchi et al., 2009). Creativity is seen as a vital means for organisations to thrive in dynamic environments, respond to unforeseen challenges and proactively develop new capabilities (Zhou and Hoever, 2014). A review of the literature indicates that key elements of an innovation 
climate include positive relationships and affective tone (Ford, 1996; Hunter et al., 2007); encouragement and support from managers and supervisors (Amabile, 1993; Hunter et al., 2007; West et al., 2004); external/outward focus and attention to customers (Lansisalmi and Kivimaki, 1999; Patterson et al., 2005; Read, 2000); risk-taking and flexibility (Ekvall, 1996; Patterson et al., 2005); job challenge and problem-solving orientation (Campbell et al., 1970; Patterson et al., 2005) and extensive internal and external communication (Ford, 1996; Lansisalmi and Kivimaki, 1999; Patterson et al., 2005).

\section{Aligning macro and micro levels}

In their recent treatise on microfoundations, Barney and Felin (2013) highlight the importance of aligning individual and collective phenomenon to examine their impact on organisational level outcomes. This sentiment is evidenced in more behavioural definitions of dynamic capabilities (e.g. Wang et al., 2015). Wang and Ahmed understand dynamic capabilities for innovation as a 'firm's ability to develop new products and/or markets, through aligning strategic innovative orientation with innovative behaviours and processes' (2007: 38). In exploring the prospective alignment of macro and micro insights, Figure 1 offers a visual representation of the microfoundations of dynamic capabilities for innovation. This illustrates a strong degree of convergence in the organisational elements which foster and sustain innovation and highlights the value of a more inclusive and holistic perspective to understanding the microfoundations of dynamic capabilities for innovation (Felin et al., 2012). Whereas dynamic capabilities reflect strategic macrolevel processes such as sensing, seizing and reconfiguration (Teece, 2007) organisational innovation strategies represent the human resource management strategies that are designed to develop these higher-order capabilities. The critical intermediary between managerial intent as reflected in innovation strategies and the manifestation of dynamic capabilities is innovative climate which captures the perceptions and feelings of employees (Dawson et al., 2008; King et al., 2007; West and Richter, 2007). Innovative climate denotes the degree to which organisational innovation strategies have penetrated the minds and experiences of employees to foster innovative work behaviour (Montag et al., 2012).

Figure 1. From microfoundations to dynamic capabilities organisational innovation strategies climate: innovation and affective behaviours dynamic capabilities outcomes microfoundations dynamic capabilities innovation outcomes

\section{Dynamic capabilities}

Organisational innovation strategies Climate: Innovation and affective behaviours Dynamic capabilities Outcomes



The evidence from the integration of the dynamic capabilities and human resource management literatures contribute to an understanding of the association between organisational innovation strategies, innovation climate and both employee and organisational innovation outcomes. The approach outlined in Figure 1 integrates the individual and organisational level processes that contribute to explaining dynamic capabilities for innovation (e.g. 
Ángel and Sánchez, 2009). Research studies have demonstrated that organisational innovation strategies such as empowerment-enhancing strategies, relationship capital and access to training are strongly associated with innovation outcomes, and that innovation climate is an important mediator in the relationship between organisational innovation strategies and innovation outcomes (Heffernan et al., 2009). Incorporating an employee dimension provides an understanding of how and why innovation strategies take effect and how the behaviours underpinning dynamic capabilities can be fostered in a systematic, dynamic and sustainable manner. Evidently in privileging capabilities as the fundamental analytical unit of analysis there has been a notable silence 'about the exercise of intelligent effort and the motivational requirements for fostering innovation' (Foss, 2009: 23). Indeed, it has been put forward that exploration of the role of talent offers one of the 'most promising' vehicles for the study of microfoundations (Barney and Felin, 2013: 146).

\section{CONCEPTUAL IMPLICATIONS}

There is growing acknowledgement that the perception of top management in the dynamic capabilities framework tends 'toward the heroic' (Lee and Teece, 2013: 34). The implications of the microfoundation argument is that dynamic capabilities are best understood as strategic higher-order capabilities which are underpinned by key processes, activities and behaviours which can be systematically designed and introduced in organisations to nurture and sustain desired employee innovation behaviour. In essence, dynamic capabilities are organisational outcomes in themselves. Viewing dynamic capabilities as higher-order organisational capabilities that are the consequences of particular complex processes and activities rather than being embodied in the activities themselves affords a clearer understanding of the nature of dynamic capabilities and how they can be developed. The logic of microfoundations addresses the key questions that lie at the nexus of individuals and organisations, with a particular focus on relationships and interactions (Ployhart and Hale, 2014). The microfoundations of dynamic capabilities are the organisational innovation strategies and innovation climate which are employed through human resource management interventions. This viewpoint also brings the perspectives and motivation of employees to the centre stage of analysis. Managing the interface between the introduction of organisational interventions and the impact of such interventions is the enabler of real change and innovation (Mossholder et al., 2011; Takeuchi et al., 2007). Important information can be gleaned here about the combined effects of particular strategies and interventions on the emotional, cognitive and social experiences of employees and ultimately on how their behaviours and dispositions towards innovation can be influenced. These help build a strong innovation dynamic characterised by innovation and affective behaviours such as knowledge sharing, co-working and committing (Kogut and Zander, 1992; Shipton et al., 2006; Takeuchi et al., 2009).

Analysing the role of employees in innovation and eliciting their perspectives, disposition, motivation and actions help to develop an understanding of how to affect collective behaviour. This provides the foundation for developing a methodology for changing the routines of employees and building routines and activities, which are aligned to creativity and innovation. The development of a model, which directs collective behaviour towards innovation and creativity, is effectively a realignment and renewal of the human resource base towards the development of microfoundations and ultimately dynamic capability in innovation. Ultimately, building dynamic capabilities requires strategic human resource management capability. This is particularly so in building innovation capability because contextual organisational factors are critically important in influencing employee creative behaviour (Rice, 2006). In making this point, we remain cautious of simplistic aggregations as highlighted by Felin and Foss (2005), but propose organisational climate as one mechanism whereby individual behaviour may be understood in an aggregate fashion to influence organisational outcomes.

\section{PRACTICAL IMPLICATIONS}

Foss (2009) argues that there is little import in suggesting that managers intervene directly at the level of a capability. Instead, managers can influence the development of capabilities 'by hiring key employees or by changing overall recruitment policies, reward systems, etc., all of which involves the microlevel' (p. 15). Arguably, microlevel phenomena are more amenable to direct intervention by management so that explanations at this level have the characteristics of being more stable, fundamental and general than more macro-level explanations (cf. Coleman, 
1990). The approach also aligns with emerging findings from the creativity literature, which suggest that an exclusive reliance on recruitment and selection as a means to promote creativity is unlikely to prove successful (Zhou and Hoever, 2014). More critical is a supportive organisational context and an infrastructure which fosters a climate for creativity. Climate can be viewed as a mediating influence between organisational practices and employee behaviours (Ekvall, 1996; West and Richter, 2007), and so forms an important element in understanding how to influence and motivate employees' creative behaviours. This understanding is particularly important as creative thinking and behaviour are difficult to orchestrate and to sustain as they require the abandonment of habitual behaviours in favour of new and less certain ones (Ekvall, 1997; Ford, 1996). Of particular interest is the notion that an innovative climate will not only simply benefit those with creative intentions, but is also likely to induce employees who lack more natural inclinations to be creative to become creative.

\section{CONCLUSION}

While calls for explorations of microfoundations are increasingly widespread and worthwhile, the reality is they form the easier part of the equation (Barney and Felin, 2013; Foss, 2009). Offering subsequent insights on how to build those foundations is a more difficult feat. The critical question demanded by the dynamic capabilities literature concerns the precise means by which an organisation can continuously renew its resource base and develop new capabilities (Al-Aali and Teece, 2014). The argument developed in this paper holds that understanding macro-level phenomenon with reference to other macro-level phenomenon offers something of a conceptual cul-de-sac, providing little insight on the nature of managerial intervention required (Abell et al., 2008; Ployhart and Hale, 2014). Instead, this paper attempted to trace the key processes, which may facilitate in fostering the type of behaviours underpinning dynamic capabilities for innovation. In so doing, it focused not only on innovation strategies as intended by management, but also critically employee perceptions of such strategies in the form of innovative climate. We align our approach with work which stresses the behavioural aspects of dynamic capabilities of innovation and how these can be systematically encouraged and nurtured (e.g. Wang and Ahmed, 2007; Wang et al., 2015). By disaggregating the processes, practices and routines which begin to create capability for innovation at lower levels in the organization, the model offers an illustrative evolutionary pathway through which dynamic capabilities can be systematically built.

This approach opens up important avenues for future research. These include embracing multiple levels of analysis to understand the aggregation and interaction of micro and macro levels (Ployhart and Hale, 2014), exploring the emergence of capabilities (Barney and Felin, 2013), and critically, directly incorporating the role of employees in the dynamic capabilities framework. More critical analysis might consider the factors likely to bridge or perpetuate the gap between intended and enacted strategy. All the while, it is important to acknowledge that concepts such as innovation and dynamic capabilities are inevitably complex and take on different meanings so that contextual and boundary conditions need to be considered and more carefully delineated (Chadwick et al., 2014). Likewise, gaining an authentic account of the impact of particular innovation strategies and dispositions and motivation of employees, and how these impacts on innovation performance will require in-depth research and multiple respondents. Nonetheless, in terms of practical relevance, we can follow the logic of those in social science generally (Coleman, 1990), and HRM in particular (Bowen and Ostroff, 2004), in arguing that the approach presented offers a useful and pragmatic basis for understanding the development of dynamic capabilities for innovation for the very reason that microfoundations are more amenable to purposeful managerial interventions as opposed to more abstract higher-order capabilities.

\section{References}

Abell, P., Felin, T. and Foss, N. (2008). 'Building microfoundations for routines, capabilities and performance links'. Managerial and Decision Economics, 29: 6, 489-502.

Al-Aali, A. and Teece, D. (2014). 'International entrepreneurship and the theory of the (longlived) international firm: A capabilities perspective'. Entrepreneurship Theory and Practice, 38: 1, 95-116.
Allen, M., Adomdza, G. and Meyer, M. (2015). 'Managing for innovation: Managerial control and employee level outcomes'. Journal of Business Research, 68: 2, 371-379.

Amabile, T.M. (1993). 'Motivational synergy: Towards new conceptualisations of intrinsic and extrinsic motivation in the workplace'. Human Resource Management Review, 3: 3, 185-201. 
Amabile, T. M., Conti, R., Coon, H., Lazenby, J., and Herron, M. (1996). 'Assessing the Work Environment for Creativity'. Academy of Management Journal, 39: 5, 1154-1184.

Ambrosini, V. and Bowman, C. (2009). 'What are dynamic capabilities and are they a useful construct in strategic management?' International Journal of Management Reviews, 11: 1, 29-49.

Anderson, N.R. and West, M.A. (1998). 'Measuring climate for work innovation: Development and validation of the team climate inventory'. Journal of Organisational Behaviour, 19: 3, 235-258.

Anderson, N., Potocnik, K. and Zhou, J. (2014). 'Innovation and creativity in organizations: A stateof-the-science review, prospective commentary, and guiding framework'. Journal of Management, 40: 5, 1297-1333.

Ángel, P.O. and Sánchez, L.S. (2009). 'R\&D managers' adaptation of firms' HRM practices'. R\&D Management, 39: 3, 271-290.

Appelbaum, E., Bailey, R., Berg, P. and Kallebery, A. (2000). Manufacturing Advantage: Why High Performance Work Systems Pay Off, Ithaca, NY: Cornell University Press.

Asmawi, A. and Mohan, A.V. (2011). 'Unveiling dimensions of organizational culture: An exploratory study in Malaysian R\&D organizations'. R\&D Management, 41: 5, 509-523.

Barney, J. and Felin, T. (2013). 'What are microfoundations?' Academy of Management Perspectives, 17: 2, 138-155.

Barreto, I. (2010). 'Dynamic capabilities: A review of past research and an agenda for the future'. Journal of Management, 36: 1, 256-280.

Becker, B. and Gerhart, B. (1996). 'The impact of human resource management on organisational performance; progress and prospects'. Academy of Management Journal, 39: 4, 779-801.

Black, S., Lynch, L. and Krivelyova, A. (2004). 'How workers fare when employers innovate'. Industrial Relations, 43: 1, 44-66.

Bowen, D. and Ostroff, C. (2004). 'Understanding HRM firm performance linkages: The role of the "strength of the HRM system"'. Academy of Management Review, 29: 2, 203-221.

Bowman, C. and Ambrosini, V. (2003). 'How the resourcebased and the dynamic capability views of the firm inform corporate-level strategy'. British Journal of Management, 14: 4, 289-303.

Boxall, P. (2013). 'Innovations in HRM series mutuality in the management of human resources: Assessing the quality of alignment in employment relations'. Human Resource Management Journal, 23: 1, 3-17.
Breznik, L. and Hisrich, R. (2014). 'Dynamic capabilities vs. innovation capability: Are they related?' Journal of Small Business and Enterprise Development, 21: 3, 368-384.

Campbell, J.P., Dunnette, M.D., Lawler, E.E. and Weick, K.E. (1970). Managerial Behaviour, Performance, and Effectiveness, NY: McGraw Hill.

Cavagnou, D. (2011). 'A conceptual framework for innovation: An application to human resource management policies in Australia'. Innovation: Management, Policy and Practice, 13: 1, 111-125.

Cepeda, G. and Vera, D. (2007). 'Dynamic capabilities and operation capabilities: A knowledge management perspective'. Journal of Business Research, 60: 1, 426-437.

Chadwick, C., Way, S., Kerr, G. and Thacker, J. (2014). 'Boundary conditions of the high investment human resource systems-small-firm labor productivity relationship'. Personnel Psychology, 66: 2, 311-343.

Coleman, J.S. (1990). Foundations of Social Theory, Cambridge, MA/London: Belknap Press of Harvard University Press.

Dawson, J.F., Gonzalez-Romá, V., Davis, A. and West, M.A. (2008). 'Organisational climate and climate strength in UK hospitals'. European Journal of Work and Organisational Psychology, 17: 1, 89-111.

Dixon, S., Meyer, K. and Day, M. (2014). 'Building dynamic capabilities of adaptation and innovation: $A$ study of micro-foundations in a transition economy'. Long Range Planning, 47: 4, 186-205.

Dosi, G. (1988). 'Sources, procedures and microeconomic effects of innovation'. Journal of Economic Literature, 26: 3, 1126-1171.

Easterby-Smith, M., Lyles, M.A. and Peteraf, M.A. (2009). 'Dynamic capabilities: Current debates and future directions'. British Journal of Management, 20: 1, s1-s8.

Eisenhardt, K.M. and Martin, J.A. (2000). 'Dynamic capabilities: What are they?' Strategic Management Journal, 21: 10, 1105-1121.

Eisenhardt, K.M., Furr, N.R. and Bingham, C.B. (2010). 'Microfoundations of performance: Balancing efficiency and flexibility in dynamic environments'. Organisation Science, 21: 6, 1263-1273.

Ekvall, G. (1996). 'Organisational climate for creativity'. European Journal of Work and Organisational Psychology, 5: 1, 105-123.

Ekvall, G. (1997). 'Organisational conditions and levels of creativity'. Creativity and Innovation Management, 6: 4, 195-205.

Felin, T. and Foss, N.J. (2005). 'Strategic organisation: A field in search of micro-foundations'. Strategic Organisation, 3: 4, 441-455. 
Felin, T. and Foss, N.J. (2009). 'Organisational routines and capabilities: Historical drift and a coursecorrection toward microfoundations'. Scandinavian Journal of Management, 25: 2, 157-167.

Felin, T., Foss, N., Heimeriks, K. and Madsen, T. (2012). 'Microfoundations of routines and capabilities: Individuals, processes and structure'. Journal of Management Studies, 49: 8, 1351-1374.

Ford, C.M. (1996). 'A theory of individual creative action in multiple social domains'. Academy of Management Review, 21: 4, 1112-1142.

Foss, N.J. (2009). 'Alternative Research Strategies in the Knowledge Movement'. European Management Review, 6: 1, 16-28.

García-Morales, V.J., Matías-Reche, F. and Verdú-Jover, A.J. (2011). 'Influence of internal communication on technological proactivity, organizational learning, and organizational innovation in the pharmaceutical sector'. Journal of Communication, 61: 1, 150-177.

Hage, J.T. (1999). 'Organizational innovation and organizational change'. Annual Review of Sociology, 25, 597-622.

Harney, B. and Jordan, C. (2008). 'Unlocking the black box: Line managers and HRM performance in a call centre context'. International Journal of Productivity and Performance Management, 57: 4, 275-296.

Heffernan, M., Harney, B., Cafferkey, K. and Dundon, T. (2009). 'Exploring the relationship between HRM, creativity and organisational performance: Evidence from Ireland'. Paper presented at the 2009 American Academy of Management Conference, Chicago.

Helfat, C.E. and Peteraf, M.A. (2009). 'Understanding dynamic capabilities: Progress along a developmental path'. Strategic Organization, 7: 1, 91-102.

Helfat, C.E. and Winter, S.G. (2011). 'Untangling dynamic and operational capabilities: Strategy for the $(n)$ ever-changing world'. Strategic Management Journal, 32: 11, 1243-1250.

Hunter, S.T., Bedell, K.E. and Mumford, M.D. (2007). 'Dimensions of creative climate: A general taxonomy'. Korean Journal of Thinking and Problem Solving, 15: 2, 97-116.

Katkalo, V., Pitelis, C. and Teece, D. (2010). 'Introduction: On the nature and scope of dynamic capabilities'. Industrial and Corporate Change, 19: 4, 1175-1186.

Kiechel, W.I. (2012). 'The management century'. Harvard Business Review, November, 63-75.

King, B.K., Chermont, K., West, M., Dawson, J.F. and Hebl, M.R. (2007). 'How innovation can alleviate negative consequences of demanding work contexts: The influence of climate for innovation on organisational outcomes'. Journal of Occupational and Organisational Psychology, 80: 4, 631-635.

Kogut, B. and Zander, U. (1992). 'Knowledge of the firm, combinative capabilities and the replication of technology'. Organization Science, 3: 3, 383-397.

Kraatz, M.S. and Zajac, E.J. (2001). 'How organisational resources affect strategic change and performance in turbulent environments: Theory and evidence'. Organisation Science, 12: 5, 632-657.

Laamanen, T. and Wallin, J. (2009). 'Cognitive dynamics of capability development paths'. Journal of Management Studies, 46: 6, 950-981.

Lam, A. (2005). 'Organisational innovation'. Chapter 5, in J. Fagerberg, D. Mowery and R. Nelson (eds), The Oxford Handbook of Innovation, NY: Oxford University Press.

Lansisalmi, H. and Kivimaki, M. (1999). 'Factors associated with innovative climate: What is the role of stress'. Stress Medicine, 15: 4, 203-213.

Lawson, B. and Samson, D. (2001). 'Developing innovation capability in organisations: A dynamic capabilities approach'. International Journal of Innovation Management, 5: 3, 377-400.

Lee, H. and Kelley, D. (2008). 'Building dynamic capabilities for innovation: An exploratory study of key management practices'. R\&D Management, 38: 2, 155-168.

Lee, S. and Teece, D. (2013). 'The functions of middle and top managers in the dynamic capabilities framework'. Kindai Management Review, 1, 28-40.

Liao, H., Toya, K., Lepak, D.P. and Hong, Y. (2009). 'Do they see eye to eye? Management and employee perspectives of high-performance work systems and influence processes on service quality'. Journal of Applied Psychology, 94: 2, 371-391.

Lynch, L.M. (2007). 'The adoption and diffusion of organizational innovation: Evidence for the US economy', NBER Working Paper 13156, National Bureau of Economic Research, Cambridge, MA.

McAdam, R. and McCreedy, S. (2000). 'A critique of knowledge management: Using a social constructionist model'. New Technology, Work and Employment, 15: 2, 155-168.

Montag, T., Maertz, C. and Baer, M. (2012). 'A critical analysis of the workplace creativity criterion space'. Journal of Management, 38: 4, 1362-1386.

Mossholder, K.W., Richardson, H. and Settoon, R. (2011). 'Human resource systems and helping in organisations: A relational perspective'. Academy of Management Review, 35: 1, 33-52.

Patterson, M.G., West, M.A., Shackleton, V.J., Dawson, J.F., Lawthom, R., Maitlis, S., Robinson, D.L. and 
Wallace, A.M. (2005). 'Validating the organisational climate measure: Links to managerial practices, productivity and innovation'. Journal of Organisational Behaviour, 26: 4, 379-408.

Ployhart, R. and Hale, D. (2014). 'The fascinating psychological microfoundations of strategy and competitive advantage'. Annual Review of Organisational Psychology and Organisational Behavior, 1, 145-172.

Ramstad, E. (2009). 'Expanding innovation system and policy - an organisational perspective'. Policy Studies, 30: 5, 1-21.

Read, A. (2000). 'Determinants of successful organisational innovation: A review of current research'. Journal of Management Practice, 3: 1, 95-119.

Rice, G. (2006). 'Individual values, organisational context, and self-perceptions of employee creativity: Evidence from Egyptian organizations'. Journal of Business Research, 59: 2, 233-241.

Rousseau, D.M. (1995). Psychological Contracts in Organisations: Understanding Written and Unwritten Agreements, Thousand Oaks, CA: Sage.

Shipton, H., West, M., Dawson, J., Birdi, K. and Patterson, M. (2006). 'HRM as a predictor of innovation'. Human Resource Management Journal, 16: 1, 3-27.

Slappendel, C. (1996). 'Perspectives on innovation in organisations'. Organisation Studies, 17: 1, 107-129.

Snell, S. and Morris, S. (2014). 'Building dynamic capabilities around organisational learning challenges'. Journal of Organisational Effectiveness, 1: 3, 214-239.

Subramony, M. (2009). 'A meta-analytical investigation of the relationship between HRM and firm performance'. Human Resource Management, 48: 5, 745-768.

Sundgren, M., Dimenäs, E., Gustafsson, J.E. and Selart, M. (2005). 'Drivers of organizational creativity: A path model of creative climate in pharmaceutical R\&D'. R\&D Management, 35: 4, 359-374.

Takeuchi, R., Chen, G. and Lepak, D. (2009). 'Through the looking glass of a social system; cross-level effects of high-performance work systems on employees' attitudes'. Personnel Psychology, 62: 1, 1-29.

Takeuchi, R., Wang, H., Lepak, D. and Takeuchi, K. (2007). 'An empirical examination of the mechanisms between high performance work systems and the performance of Japanese organisations'. Journal of Applied Psychology, 92: 4, 1069-1083.
Teece, D.J. (2007). 'Explicating dynamic capabilities: The nature and microfoundations of (sustainable) enterprise performance'. Strategic Management Journal, 28, 1319-1350.

Teece, D. (2012). 'Dynamic capabilities: Routines versus entrepreneurial action'. Journal of Management Studies, 49: 8, 1395-1401.

Teece, D.J., Pisano, G. and Shuen, A. (1997). 'Dynamic capabilities and strategic management'. Strategic Management Journal, 18: 7, 509-533.

Thompson, M. (2007). 'Innovation in work practices: A practice perspective'. The International Journal of Human Resource Management, 18: 7, 1298-1317.

Wang, C.L. and Ahmed, P.K. (2007). 'Dynamic capabilities: A review and research agenda'. International Journal of Management Reviews, 9: 1, 31-51.

Wang, C., Senaratne, C. and Rafiq, M. (2015). 'Success traps, dynamic capabilities and firm performance'. British Journal of Management, 26: 1, 26-44.

Watson, D., Galway, J., O'Connell, P. and Russell, H. (2010). The Changing Workplace: A Survey of Employers' Views and Experiences, Dublin: National Centre for Partnership and Performance.

Wei, L.Q. and Lau, C.M. (2010). 'High performance work systems and performance: The role of adaptive capability'. Human Relations, 63: 10, 1487-1511.

Wendelken, A., Danzinger, F., Rau, C. and Moeslein, K. (2014). 'Innovation without me: Why employees do (not) participate in organizational innovation communities'. R\&D Management, 44: 2, 217-236.

West, M.A., Hirst, G., Richter, A. and Shipton, H. (2004). 'Twelve steps to heaven: Successfully managing change through developing innovative teams'. European Journal of Work and Organisational Psychology, 13: 2, 269-299.

West, M.A. and Richter, A. (2007). 'Climates and cultures for innovation and creativity at work', in J. Zhou and C.E. Shalley (eds), Handbook of Organisational Creativity, Mahwah, NJ: Lawrence Erlbaum Associates, Inc.

Zheng, W. (2010). 'A social capital perspective of innovation from individuals to nations: Where is the empirical literature directing us?'. International Journal of Management Reviews, 12: 2, 151-183.

Zhou, J. and Hoever, I. (2014). 'Research on workplace creativity: A review and redirection'. Annual Review of Organisational Psychology and Behaviour, 1, 333-359.

Zollo, M. and Winter, S.G. (2002). 'Deliberate learning and the evolution of dynamic capabilities'. Organization Science, 13: 3, 339-335. 